\title{
Universidade Pública, Alienação e Produção Científica do Direito*
}

\author{
Jacinto Nelson de Miranda Coutinho**
}

Este trabalho, O Arquivamento e o Princípio da Obrigatoriedade, do João Pedro Gebran Neto, tem muitas virtudes, dentre as quais é necessário destacar algumas, não somente pelo deleite da enumeração mas, sobremaneira, para anotar e discutir aquilo que não está aparente, mormente em um tempo onde as pessoas teimam em não observar o que, em verdade, interessa. A alienação é imanente à lógica pós-moderna, sobretudo pelo viés neoliberal.

Com efeito, estamos convivendo com um mundo onde a comunicação é pilar fundamental e, por ela, passam os mecanismos mais perversos de controle da racionalidade, do mundo, dos quais ninguém escapa. Estar - ou ser - alienado é, destarte, uma manifesta forma de gozo, como diria Lacan. O complicado, porém, é tentar responder até quando poderemos suportar, na base da anestesia imaginária, as condições atuais, cientes todos, desde logo, que coisas reais como a fome, por exemplo, não se prestam a prolongados sonos ideológicos.

Sem embargo, estão estendendo o elástico da suportabilidade do ser humano com jogos discursivos que, a toda evidência, não fundam nada, a não ser o risco da catástrofe, por um lado e, por outro, a manutenção do bem-estar de alguns, poucos, pouquíssimos, em se olhando para a imensidão dos desafortunados, dos postos-à-sorte-no-mundo. Se não soubéssemos a razão de tudo isso, posto descortinada a farsa, teríamos como incrível o fato de permitirmo-nos chegar em tal situação. De qualquer forma, extasia a naturalidade como tudo é aceito, como diria Agostinho Ramalho Marques Neto.

* O presente artigo é o prefácio, escrito pelo Prof. Jacinto Nelson de Miranda Coutinho, do livro "O arquivametno e o princípio da obrigatoriedade", de João Pedro Gebran. Sua publicação nesse espaço explica-se pela abordagem que dá acerca das questões universitárias no Brasil, assim como pela pertinência com o debate sobre o ensino e a pesquisa levado a efeito no âmbito de nossos Cursos de Pós-Graduação.

** Professor de Direito Processual Penal na UFPR.

Revista da Faculdade de Direito da UFPR, Curitiba, a. 29, n. 29, 1996, p. 247-253 
Por elementar, faz-se presente uma contra racionalidade se, por tal, tomamos aquela que nos foi legada por Tomás de Aquino e consagrada, nos moldes atuais, a partir da Revolução Francesa. Por certo, no mundo de hoje, pacto, contrato, direitos humanos (entre outros), são elementos que devem contar muito pouco; coisas "velhas", ultrapassadas; tradição, no mau sentido. Por evidente, nesta folie, vê-se bem a inversão completa dos valores, naturalmente despercebida quando a alienação acaba por jogar irmão contra irmão (o que seria a Bósnia?), o homem contra si mesmo quando se oferece em holocausto em nome de uma farsa que imputa ao Estado o grande crime, mas que lhe come pelas entranhas da esperança. Ora, é inimaginável que um ser humano normal, ciente da sua cidadania, troque as suas conquistas constitucionais, marcadas por rios de sangue, pelas quimeras de um discurso flatuoso, como diria Lyra Filho. E pensar que a racionalidade legada pela escolástica, para nós da periferia do mundo, sempre foi imprestável, na sua mais larga extensão, porque totalitária (Dussel) e, consequentemente, excludente; se assim se pudesse falar, deu-nos um ideal de ego pífio (ainda que fosse - e é - uma crença), mormente porque o ego ideal (a racionalidade total) sempre mostrou-se furado, salvo para os ingênuos e/ou ventríloquos, acostumados a tentar gozar com os objetos alheios. Para tanto, basta pensar no desejo, como faz a psicanálise. De qualquer forma, é preciso ter sempre presente que não se volta atrás em conquistas democráticas!

Mas não é só com essa tentativa que convivemos, sem embargo dela estar na matriz. O efeito direto dela é a "crise", da qual tanto se fala que, em verdade, começamos todos a duvidar que efetivamente exista, ou seja, desde sempre falou-se em crise e, portanto, ela não é a exceção, mas a ordem. Por certo, não se sabe bem se estamos diante de uma crise da ideologia ou de uma ideologia da crise, como diria Joaquín Herrera Flores. Sabemos, não obstante, sem querer estar iludidos, que a precitada "crise", nos países centrais, é uma crise de "terceira idade", isto é, pelos caminhos tortuosos dos jogos econômicos e políticos (a necessidade do voto faz infames prometerem - e escreverem em leis - o que não podem - os outros, do próximo governo, por elementar -, cumprir), foram eles levados à inusitada situação de inadimplência quanto à cidadania, razão pela qual têm que conviver com o estupor dos inimagináveis "cortes", tidos e havidos até bem pouco tempo atrás como remédios de cariz ditatorial, absolutamente inaceitáveis. Eis, então, "a crise", em ultima ratio: voltar atrás nas 
conquistas democráticas, ou seja, fazer o cidadão deixar de contar alguma coisa.

Para nós, a situação poderia não ser assim. Afinal, não é crível que tenhamos uma "crise de terceira idade" sem jamais termos saído dos cueiros. Pois! Em países periféricos, a grande luta sempre foi, na raiz, buscar consagrar as conquistas democráticas e, depois, dar efetividade às normas constitucionais. Antes disso suceder, porém, no caso brasileiro, tem-se a impressão que estamos na mais profunda crise, por evidente que em nome de uma ideologia capitalista selvagem, malvada e, pior, que não sabe para onde vai, razão por que se estrutura de maneira esquizofrenóide, a golpes de "imbroglio" retórico.

O liberalismo, como referido e todos sabem, nunca foi grande coisa, tanto que sistematicamente vinha denunciado, no caso dos países periféricos, porque não se cumpria com o mínimo prometido. Não matava, contudo, a esperança; algo sobrava para sonhar, para viver. Agora, com o prefixo neo para não deixar dúvida que se trata de algo vário, o neoliberalismo faz sucumbir o liberalismo, isto é, deixa claro que este não pode, na essência, sobreviver. Estamos, de fato, mal. Ainda que não queiramos aceitar, estão tentando consagrar, definitivamente, o the dream 's over. Mas nem toda frase é palíndromo; e uma hora faz-se a revolta do real contra o imaginário.

$\mathrm{Na}$ esteira da privatização do espaço público, o que não se tem presente é a sua dimensão. O Estado, na visão neoliberal, é um empecilho; necessário para coisas miúdas, aí compreendidos os Poderes, inclusive o Judiciário. O direito - e os direitos-, por conseqüência, há de ser desprezado, a ponto de não ser considerado como imaginado por aqueles "visionários" da modernidade.

$\mathrm{Na}$ seqüência, avançam - para ficarmos tão-só em um exemplo do qual o presente trabalho é bastião indestrutível - contra o ensino público, principalmente aquele da Universidade Pública. Que safadeza! Pior: o combate segue o infantil discurso do custo (mas teria outro uma racionalidade economicista?), bradando-se ao vento pelos "bilhões" desperdiçados. Como disse Paulo Franis, no seu Diário da Corte de 28.03.96 (Zero Hora, Porto Alegre, Segundo Caderno, p. 4), em subtítulo denominado "Assalto", "As universidades do Estado (federais) por ano gastam $\mathrm{R} \$ 4,25$ bilhões, de um orçamento de $\mathrm{R} \$ 5$ bilhões, rubricados para 
o ensino superior. Divididos por aluno, este sai para o Estado por 12.050,00 por ano. (...) Na escola privada, a média é de $\mathrm{R} \$ 4.668,00$ ao ano, perto de $\mathrm{R} \$ 4$ mil per capita. O estudante particular sai $38,41 \%$ mais barato que um aluno 'gratuito' do Estado." Há, aqui, como parece primário, se a informação for correta, algo visível (a tentativa de jogar a opinião pública contra as Universidades Públicas, sob o fundamento de que "O dinheiro não é investido no estudante. É despesa de professores e burocracias que administram o sistema, o cabide clássico de empregos que marca o nosso serviço público", o que pode ser conseguido se a alienação não for superada) e algo oculto, mas importante na venda da mensagem, ou seja, a falta de outros dados que são imprescindíveis. Com efeito, é preciso dizer, também, entre outras coisas, que o Estado subsidia o ensino privado, e, mais importante, que neste país só se faz pesquisa na Universidade Pública. Ora, quanto custam os laboratórios, os hospitais, os parques de máquinas, os aparelhos astronômicos e metereológicos, as bibliotecas? Quem lucra, não obstante, é quem se serve do resultado dessas pesquisas, industrializando-as. Em sintese: o Estado, por sua Universidade Pública, financia os detentores do capital; e de sobra oferece, graciosamente, a melhor mão de obra quando dá, na patena, à submissão laboral, os filhos da classe média e baixa, por que não é preciso ser gênio para concluir que aqueles poucos ricos que temos estudam fora, no estrangeiro, (de)formando-se por uma racionalidade que não condiz com a sua realidade.

Temos, então, a seguinte situação: não vão permitir que se pare (a não ser que os nossos capitalistas sejam tão ignorantes, o que não é verdadeiro) com a pesquisa; mas não vão fazer os pais dos alunos do ensino universitário público pagar uma mensalidade de mais de $R \$ 1.000,00$ por mês, até porque não se tem. De algum lado, parece visível, a corda vai estourar; e não será, por óbvio, daquele onde estão os detentores do poder. A opção final, aos desavisados (eis o resultado da alienação!), será não permitir que seus filhos estudem (ou escolher entre eles, em algumas hipóteses), como ocorria no tempo dos nossos pais, onde os avós, imigrantes, conscientes da importância do estudo, tinham que optar pelo filho que iria à escola. Agora, se assim é, pode ser que os mesmos personagens que, iludidos, pregam a privatização, emprenhados pelo discurso global, acabem por sacrificar a si e aos seus, tal e qual na história de um famigerado assalto à poupança popular praticado através de Brasília, do governo federal, em nome de "interesses maiores". Enquanto isso, à latere, os jornais televisivos da semana passada (última de março), 
noticiavam, sem que nos causasse grande estupor (a banalização do cotidiano já não nos permite grande assombro com o número de mortos, escândalos públicos e outras infâmias ao gênero humano, seduzidos que estamos pela melodramatização da vida), que os centros de pesquisas da Universidade Federal da Bahia e Universidade Federal do Rio de Janeiro, em conjunto, acabaram de desenvolver um sistema de computação à medicina que possibilitará fazer diagnósticos cardíacos de grande precisão, ainda sem a presença de um especialista, ou seja, na maioria dos lugares onde vive este Brasil. Em suma, qualquer médico oferece dados preestabelecidos à máquina que, de imediato, fornece um diagnóstico, recomendando um tratamento temporário e encaminhamento do paciente a um centro especializado. Assim, estes "chupins" da Universidade Pública, propiciarão que se salvem milhares de vidas. Mas o que conta isso se os eventuais sobreviventes, na extragrande maioria, não são de homo oeconomicus, mas de homo famelicus? Que responda a racionalidade neoliberal!

Como dito, o excelente trabalho do João Pedro Gebran Neto, realizado como conclusão de um Curso de Especialização em Ciências Penais, na Faculdade de Direito da Universidade Federal do Paraná, hoje extinto (não havia qualquer condição material ao seu prosseguimento) porque não há abnegação que suporte tal fardo, é produção de tamanha qualidade que, mutatis mutandis, comparado ao exemplo precitado, também pode salvar vidas; basta pensar o que a cadeia representa, em vista da AIDS, para um garoto de dezoito anos. Em verdade, uma monografia de conclusão de especialização não precisa, mesmo, ser melhor que a presente. Ademais, um trabalho assim não pode ser destruído por um discurso enganador!

Com efeito, discutir O Arquivamento e o Princípio da Obrigatoriedade, mormente da forma como efetivada, é jog ar luz sobre um espaço do processo penal marcado por um "vazio" legislativo e, de conseqüência, uma nebulosa doutrina, não fosse também uma despedaçada - complicada e não raro errada - jurisprudência.

A matéria que toca com o arquivamento e o desarquivamento do inquérito policial, na sua extensão mais ampla, para além da "falha" legislativa, exige, por suas características, uma intervenção subjetiva de tal envergadura que coloca à descoberto a pretensa "segurança jurídica", tanto louvada a partir do princípio da legalidade, principalmente pelos leguleios, que ainda acreditam em miragens, feu follet. A legalidade é imprescindível, 
sim, mas sendo um espaço "da lei", não pode ser mais que meta optata. Afinal, enquanto o homem contar alguma coisa, não pode ser excluído. E falar em homem é falar, também, em inconsciente, no Outro (com maiúscula), como diria Lacan, ou seja, do "inferno" desconhecido, que nos "atenta" a cada segundo, mas nos oferece aquilo que sabemos que é bom, embora possa não ser permitido. No fundo, é desse "inferno" dos seus "eus" que os pretensos garantistas do dito Movimento da Lei e Ordem (sobre o assunto é indispensável verificar o pensamento de gente séria como Alessandro Baratta e Winfried Hassemer) têm medo, ainda que, no discurso, queiram a "cabeça" dos desviantes.

Então, é natural louvar-se um trabalho que trata de dar conta do juízo de admissibilidade da ação, tratando das condições da ação (corretamente, como há muito tem-se pensado no Paraná, mormente a partir de Jorge de Figueiredo Dias, como fizeram Fernando Newton Bittencourt Fowler e Antonio Acir Breda), assim como outras hipóteses de arquivamento. Ora, não é mais suportável a mera transferência acrítica das condições da ação do processo civil para o processo penal. Assim, possibilidade jurídica do pedido, interesse de agir e legitimidade ad causam, em um processo penal onde, do ponto de vista de uma teoria honesta não se pode vislumbrar qualquer lide, nada dizem. Tipicidade aparente, punibilidade concreta, justa causa e legitimidade de parte, por outro lado, preenchem o espaço das condições da ação, no processo penal, de modo a não deixar qualquer saudade das fórmulas civilísticas; e hoje fazem estrada na processualística penal brasileira. Mais importante que isso, não obstante, é o fato de que fornecem um suporte teórico capaz de garantir um salutar julgamento quanto à admissibilidade da ação e arquivamento do procedimento preliminar. Ademais, é preciso, desde logo, compreender que se trata, nos dois casos, de decisões; e não meros despachos, como insiste-se até hoje, onde, não poucas vezes, o magistrado, sem nada analisar, simplesmente assina um carimbo aposto nos Autos em cartório. Neste momento, a magistratura fala contra si mesma; e em geral por falta de um maior - e melhor - conhecimento. Em verdade, aqui, o João Pedro Gebran Neto fez o que já deveríamos ter feito há muito tempo, inclusive para facilitar o conhecimento e divulgação dessa visão teórica. Não é possível, contudo, operar e ocupar todos os espaços.

De outro ponto de vista, o trabalho é fundamental para os alunos. Será, com certeza, texto de imprescindível leitura, de modo que deverá ser 
adotado por qualquer professor que não queira perder a melhor evolução da matéria.

At last but not at least, há de se louvar o esforço e valor do autor. Recém-formado, preparou-se, prestou concurso e foi aprovado no Ministério Público do Paraná; mas não parou de estudar. Durante um ano freqüentou, assiduamente, o Curso de Especialização, deslocando-se do interior, com imenso sacrifício para sua família. Teve garra, tão ausente nos jovens de nossos dias, aos quais, inadvertidamente, quer-se dar tudo. Lutando, superou o concurso para Juiz Federal, indo emprestar seu brilho à magistratura, onde está atuando. Não se deitou, todavia, em berço esplêndido: continua achando que juiz deve estudar; e muito. E é isso que procura fazer, razão por que tratou de revisar e publicar seu trabalho conclusivo da especialização. Ademais, juntamente com outros amigos juízes - também conscientes da realidade e de suas necessidades -, implementa um grupo de estudos no seio da Justiça Federal, em Curitiba. Aqui - isto é visível há muito - reside a possibilidade (não a única, mas a factível) de redenção da magistratura nacional: Sócrates, Platão, Aristóteles, Freud, Lacan e tantos outros têm tudo a dizer, inclusive naquilo que possa ser um juiz ajudar, sem arrogância, outro, até porque o troco vem logo, muito, muito rapidamente. O juiz, entenda-se bem, continua sendo um homem, apesar de juiz e ainda que muitos tentem enganar-se dizendo que não e lutando contra o óbvio, não fosse a própria natureza. É preciso aterrar!

Temos orgulho, na Faculdade de Direito desta que é a mais antiga Universidade do Brasil, a UFPR, de ter tido um aluno do quilate do autor.

Curitiba, abril de 1996 